\title{
A ANÁLISE ECONÔMICA DO DIREITO EM SUA PERSPECTIVA TRANSNACIONAL COMO MEIO DE FOMENTO DAS POLÍTICAS DE AUSTERIDADE
}

\author{
THE LAW AND ECONOMICS IN ITS TRANSNATIONAL PERSPECTIVE AS A \\ MEANS FOR PROMOTING AUSTERITY POLICIES
}

\begin{abstract}
Márcio Ricardo Staffen
Doutorado em Direito Público pela Università degli Studi di Perugia - Itália (2015). Doutorado em Ciência Jurídica pela Universidade do Vale do Itajaí (2014), Mestrado em Ciência Jurídica pela Universidade do Vale do Itajaí (2011), Graduação em Direito pela Universidade do Vale do Itajaí (2009). Professor Permanente do Programa de Pós-Graduação Stricto Sensu em Direito - IMED e Coordenador do Programa de Pós-Graduação Stricto Sensu em Direito (2014-2018).
\end{abstract}

Gustavo Polis

Mestrado em Direito em andamento pela Faculdade Meridional - IMED, Graduação em Direito pela Faculdade Meridional - IMED (2019).

\section{Resumo}

O presente trabalho busca discorrer acerca do Direito inserido nas relações do mundo "sem fronteiras". Nesta senda, observa-se como problema de pesquisa a ser aqui enfrentado: os agentes privados transnacionais, ao difundir a mundialmente a Análise Econômica do Direito, fomentaram as políticas de austeridade? Através do método indutivo, baseado em pesquisas e análises bibliográficas, tem-se como objetivo discorrer como se dá a confecção do direito em cenários transnacionalizados perpassando pela influência exercida pelos diferentes atores da globalização no processo legislativo em escala mundial, em especial naquilo que diz respeito a difusão da ideia de austeridade por meio do uso da Análise Econômica do Direito.

Palavras-chave: Análise Econômica do Direito. Austeridade. Instituições Transnacionais.

\begin{abstract}
The present work intends to expatiate about Law inserted in the "borderless" relations word. On this pass, it is observed as a research problem to be faced here: did the transnational private agents, by disseminating to the world the Law and Economics, fomented austerity policies? Through the inductive research method, based on researches and bibliographical analyzes, the objective is to discuss how lawmaking takes place in transnationalised scenarios through
\end{abstract}


the influence exerted by the different actors of globalization in the legislative process on a world scale, especially with regard to diffusion of the idea of austerity through the use of Economic Analysis of Law.

Key-words: Law and Economics. Austerity. Transnational Institutions.

\section{CONSIDERAÇÕES INICIAIS}

O problema central do trabalho que se apresenta é a ampla compreensão do fenômeno da globalização, ocasionando a criação de empresas e instituições transnacionais capazes de atuar e influir em espaços antes dominados exclusivamente pelo Estado Soberano, culminando com a disseminação de políticas de austeridade através do emprego da chamada Análise Econômica do Direito (AED). Através do método indutivo, baseado em pesquisas e análises bibliográficas, tem-se como objetivo discorrer como se dá a confecção do direito em cenários globalizados perpassando pela influência exercida pelos diferentes atores da sociedade global no processo legislativo em escala mundial, em especial naquilo que diz respeito a difusão da ideia de austeridade por meio do uso da Análise Econômica do Direito.

O direito enquanto construção social aplicada, tem como condição primeira a procura de instrumentos de limitação dos poderes. Já não é apenas um meio de ordenação social. Nessa linha de pensamento, necessita guardar em seu bojo uma perspectiva de funcionalidade social. O surgimento de novas matrizes de poder exige um novo direito de contenção dos excessos provindos das mudanças. Os processos globalizatórios criaram um mercado mundial, uma nova ordem supra e transnacional que permite a livre circulação de capitais, mercadorias, bens e serviços. Criou-se espaço para o exercício de um poder hegemônico de natureza técnico, econômico e financeiro espraiado pelo mundo, a qual desencadeou uma drástica redução do Estado Nacional e institui instrumentos de uma global governance.

A partir da fragilidade dos tradicionais atores nacionais, espaços de debilidade passaram a serem ocupados por interesses transnacionais constituídos por novas instituições. Exemplo desse cenário é a atuação de organismos de caráter transnacional, como a Troika no âmbito da União Europeia, a qual é constituída pela união da Comissão Europeia, do Banco Central Europeu e do Fundo Monetário 
Internacional, sendo responsável por confeccionar planos e estratégias em programas de assistência financeira na zona do euro.

Ao passo em que esse segmento de atores se desenvolveu, de igual sorte, concomitante ao empoderamento de tais organismos, a doutrina neoliberal se originou e ganhou envergadura. Nesse ínterim, para a reclassificação do Estado Social sob o viés da lógica dos custos e austeridade, a construção de um instrumento capaz de remover os obstáculos no caminho da maximização da riqueza ainda era necessária. Esse movimento foi chamado de Law and Economics, ou Análise Econômica do Direito. Influenciado pelo neoliberalismo, tal movimento nasce nos anos 1960, buscando a aplicação de conceitos econômicos na ciência jurídica, no intuito de inculcar uma racionalidade econômica dentro da dogmática do Direito.

Com escopo de exemplificar o novo paradigma global, onde o Direito se modifica através do uso de critérios econômicos na ciência jurídica, fomentados por instituições de matriz transnacional, serão analisados, no artigo que se apresenta, dois casos emblemáticos que permeiam a temática, quais sejam: A realização da chamada Reforma Administrativa brasileira no ano de 1998,que estabeleceu parâmetros de eficiência para a administração estatal, pautados por uma forte contenção de gastos por parte do Estado e a atuação da Troika em Portugal durante a crise financeira que se instalou naquele país a partir de 2010.

\section{TRANSNACIONALIDADE E OS NOVOS ATORES TRANSNACIONAIS}

Durante toda a fase seguinte à chamada Paz de Westfalia, o Direito foi progressivamente visto como um aparato tipicamente estatal, exclusivamente oriundo do ente estatal e do monopólio da força sobre a qual a soberania encontrava fundamento (CRUZ; OLIVIERO, 2013, p. 33).. Todavia, a confecção jurídica, na era da globalização, busca transformar esse paradigma ao propor um esquema, de certo modo, relacional, até então desconhecido, tendo como ponto fundamental a centralidade do indivíduo como entidade "libertada" das relações comunitárias, fazendo com que o Órgão judicial perca seu caráter de territorialidade.

Entretanto, mais do que falar em uma suposta "superação" do direito estatal, é preferível falar-se em uma transformação deste, a qual encontra explicação na hegemonia exercida, em especial, pelo fator econômico no âmbito do raciocínio jurídico (CRUZ; OLIVIERO, 2013, p. 33). Deve-se ter em mente a existência e 
relevância de novos tipos de poder transnacionais que não são limitados por qualquer tipo de direito nos moldes clássicos da teoria jurídica.

Com a proliferação do fenômeno da globalização espaços de debilidade passaram a ser ocupados, face a grande fragilidade dos tradicionais atores nacionais, em maior escala após a Segunda Guerra Mundial, por uma agenda de interesses transnacionais constituída através de instituições novas, de difícil caracterização à luz do glossário político-jurídico da modernidade. A homogeneidade tradicional no pensamento político e jurídico fora intensamente perdida. Instalou-se, assim, um cenário de grande tensão institucional, onde as antigas instituições do Estado e os indivíduos depararam-se com uma sensação de profunda insegurança (STAFFEN, 2015, p. 34). Por assim dizer, a força motriz do Direito já não mais são anseios de limitação jurídica dos poderes estatais absolutos, mas a regulação de dinâmicas policêntricas atreladas diretamente com a circulação de modelos, capitais, pessoas e instituições distribuídos tanto em espaços físicos como nos virtuais.

Nesse contexto, a capacidade de o ente estatal produzir, soberanamente, os sistemas jurídicos nacionais vem, paulatinamente, diminuindo. Isso ocorre, em grande parte, porque as próprias opções políticas abertas às maiorias parlamentares encontram-se reduzidas à constante concessão de soberania à "comunidade transnacional", principalmente por meio de instituições como o Fundo Monetário Internacional, a Troika, a ONU e suas agências, bem como as grandes corporações transnacionais que criam uma espécie de "estado de necessidade econômica" através do exercício de seus tentáculos de influência (CRUZ; OLIVIERO, 2013, p. 34), redefinindo, portanto, o cerne da capacidade legislativa do Estado.

Como já demonstrado, a interação de diferentes atores na vida pública e privada no âmbito da sociedade "sem fronteiras" é deveras intensa. Todos estes agentes (Organizações Não Governamentais, Empresas, Companhias e os próprios Estados) existem inseridos em um mesmo contexto cultural, filosófico e econômico, pautados por valores e regras que compartilham entre si, em uma espécie de cooperação global (partnership) (BRASIL, 2001, p. 38).

Insta salientar que grande parcela do mérito para a confecção dessa network deve-se ao profundo desenvolvimento científico e tecnológico característico da segunda metade do século XX, ao passo em que encurtaram as distâncias do globo terrestre, fomentando o intercâmbio cultural em todos os níveis (BRASIL, 2001, p. 40). Essa transformação desenvolveu-se e propagou-se como uma rede de nós rígidos e 
malha elástica, onde cada especto está em contraposição com os demais, por exemplo, o progresso tecnológico permitiu, e permite, uma melhor organização das fábricas, e estas, por sua vez, aceleram o processo tenológico.

Compulsando a recente história da Globalização, esta até mesmo confunde-se com o desenvolvimento e proliferação das chamadas Instituições Transnacionais. Durante a década entre os anos de 1950 e 1960 as grandes empresas, tal qual diversos outros organismos de matriz privada ou público-privada, passaram a experimentar e serem influenciadas pelo forte intercâmbio cultural e jurídico mundial, como consequência, entraram em um processo de multinacionalização (RADU, 2009, p. 399), disseminando seus diversos bens e serviços além das fronteiras do país onde iniciaram suas atividades, inaugurando, dessa forma, uma economia global, independente de pressões estatais, pautada com grande influência de correntes privadas, de caráter transnacional, sendo seus agentes a exemplo dos bancos, organizações internacionais e agências reguladoras, os atores protagonistas desse cenário.

Pode-se anunciar alguns exemplos para elucidar e ilustrar este novo palco de cooperação oriundo do novo paradigma global. Composta por organismos de normatização, de matriz híbrida público-privada, a Organização Internacional para a Estandardização (ISO) tem criado pontes entre setores públicos e privados, mas, com atribuições de cunho regulamentar iminentemente públicas. Caso similar é o ocorrido quando da aderência de diversos Estados ao Comitê da Basiléia, entidade de caráter nacional, com escopo de regimentar as atividades bancárias à níveis mundiais. Ainda, como maior expoente deste tipo de relação observa-se o caso do regimento da Internet, cuja responsabilidade de regular o uso da ferramenta encontra-se no escritório de uma empresa público-privada - a ICANN, Internet Corporation for Assigned Names - que acaba por prestar um serviço público destinado a todo o globo (STAFFEN, 2015, p. 28), promovendo, assim, uma interação entre os diferentes partícipes da atual sociedade globalizada, inclusive, tornando laboriosa a caracterização desses como sendo agentes públicos ou privados.

Nesta mesma linha, há instituições exclusivamente privadas que transitam com frequência neste novo espaço mundial, cujas relações de dependência em relação aos entes públicos e estatais é, de fato, inexistente. Possivelmente os maiores exemplares desse formato de instituição sejam a Federação Internacional de Futebol Associado (FIFA) e da Câmara Internacional do Comércio (ICC), as quais 
desenvolvem seus trabalhos de maneira completamente autônoma, inclusive elaborando normas acerca daquilo que lhes é de interesse, com o fito central de promover o comércio e demais investimentos internacionais, e para isso, fazem-se parceiras importantes de organismos nacionais, internacionais e transnacionais (STAFFEN, 2015, p. 29), influenciando cada uma dessas instituições parceiras a seu modo e conveniência.

Não sem razão, depreende-se do atual contexto que a governança global vai muito além da elaboração de leis e o estabelecimento das diferentes modalidades de regras. Ao olhos do indiano, especialista em relações internacionais, Parag Khanna, este ambiente de caos pode encontrar alguma ordem no desenvolvimento de uma "megadiplomacia" (KHANNA, 2011, p. 33), a qual deve buscar o apaziguamento entre os diferentes atores da arena mundial, destrancando, assim, recursos de ONG's, corporações, instituições transnacionais, bem como de governos para que estes atuem em um mesmo sentido, possibilitando a realização de empreendimentos conjuntos, de amplo alcance, capazes de fazer frente as questões resultantes do estabelecimento de uma comunidade transnacionalizada.

O extenso processo de transferência de poder das economias nacionais para o livre mercado, pautado pelos mercados globais, pode ser classificado como a mudança mais importante ocorrida no século XX, sendo levada a feito devido ao poder e a influência das empresas e organismos de caráter transnacional, assim como pelo advento das networks nas quais operam em escala mundial (RADU, 2009, p. 402). Consequentemente, é perceptível a proliferação de instituições privadas envolvidas no trato de assuntos que dizem respeito a regulação de assuntos globais nos mais diversos campos, como a proteção do meio ambiente, do direito à alimentação, a tutela da propriedade intelectual e outros tantos.

\section{A DIFUSÃO DA ANÁLISE ECONÔMICA DO DIREITO}

Com a inegável ascensão das Instituições Transnacionais, estas fomentaram largamente a confecção de ferramentas capazes de facilitar a atuação e a livre circulação do mercado financeiro global. Giza-se, não sem demora, nesse quadro, a figura da Análise Econômica do Direito como um subproduto da proliferação do ideário neoliberal no campo da ciência jurídica. Destarte, abre-se espaço para a conceituação e entendimento da chamada Law and Economics, bem como seus efeitos no âmbito dos direcionamentos das políticas estatais. 
Após o segundo pós-guerra, a proeminência de um Estado de Bem-Estar na Europa, naquele momento destruída por uma batalha sem precedentes, serviu ao mundo como um impulso para levar-se a efeito uma política de justiça social distributiva (MORAIS DA ROSA; MARCELINO JÚNIOR, 2009, p. 9). Por outro lado, no Brasil e em maior parte da América Latina, um modelo desenvolvimentista foi amplamente difundido, o qual buscava um incessante crescimento econômico, buscando equiparar-se com os chamados países desenvolvidos, para só assim, depois, implementar o tão almejado Estado de Bem-Estar Social.

No ano de 1988, no entanto, uma nova ordem constitucional é inaugurada, de maneira democrática, ocorrendo, entretanto, um tanto quanto tarde demais, por assim dizer. A nova Constituição é adota no Brasil quando o modelo político-econômico imperante é frontalmente incompatível com os propósitos basilares do Estado Constitucional ora vigente. Esse modelo é chamado de neoliberalismo (MORAIS DA ROSA; MARCELINO JÚNIOR, 2009, p. 10). Nesse contexto, a nova lógica social - de Mercado - estabelece que normas constitucionais garantidoras de Direitos Fundamentais passem a ser interpretadas sob a égide da relação custo-benefício, pois, aos olhos da teoria neoliberal, os direitos sempre implicariam um custo ao erário. O Direito, nesse viés, passa a ser reduzido a mero "instrumento" de uma ideia econômica.

Outrossim, a reclassificação dos Direitos Fundamentais sob o viés da lógica dos custos ainda necessitava de um instrumento capaz de remover os obstáculos no perverso caminho da maximização da riqueza. Esse movimento foi chamado de Law and Economics, também conhecido como Análise Econômica do Direito (AED) (MORAIS DA ROSA; MARCELINO JÚNIOR, 2009, p. 16). Fortemente influenciado pelo liberalismo econômico, tal movimento surgiu no início da década de 1960, na Universidade de Chicago, eis que seus estudiosos passaram a elaborar conceitos e meios para a aplicação e interpretação da ciência jurídica através de conceitos provindos da ciência econômica. O movimento busca, portanto, transformar o Direito, o qual estaria ainda em um estado pré-científico, incapaz de se adaptar à nova realidade mundial, pautada pela profunda crise do Estado de Bem-Estar Social, em uma ciência na verdadeira acepção do termo, racional e positiva, e, para tal, realizaria uma análise e investigação do fenômeno do Direito como um todo, em consonância com os princípios, categorias e métodos empregados pelo pensamento econômico. 
Em sua obra Economic Anslysis of Law, um dos corolários da AED, datada de 1973, Richard Posner se utiliza da economia para construir uma teoria explicativa dos institutos jurídicos, considerando que tais dispositivos podem ser explicados como resultado da maximização de forma relativamente coordenada de preferências individuais (HEINEN, 2014, p. 319). De igual sorte, propõe uma teoria normativa, em que avalia como as normas legais e sanções afetam o comportamento dos indivíduos e, utilizando-se dos pressupostos econômicos, quais seriam as normas jurídicas mais eficientes.

Posner deriva três fundamentos principais da economia a partir desta proposição: a) a lei da demanda; b) equilíbrio competitivo e c) o mercado livre é eficiente. Com apoio nesses pressupostos fundamentais, o jurista americano pretendeu construir uma nova teoria jurídica unificada a partir da contribuição da economia. O pressuposto aqui assumindo pelo estudioso, no intuito de levar a feito a construção de sua AED é de que a função do direito é facilitar a operação dos mercados livres e, onde haja custos de transações proibitivos, o direito deveria imitar o mercado, criando o resultado a ser esperado caso as transações fossem factíveis (HEINEN, 2014, p. 320). Para isso, Posner se vale de três chaves para compreender as questões de teoria do direito: a economia, o pragmatismo e o liberalismo.

Desta feita, na concepção da Análise Econômica do Direito, os textos jurídicos são singelos meios para a escolha da melhor decisão, única e exclusivamente conforme o critério econômico, não sendo os critérios hermenêuticos do direito uma preocupação central, afinal estes não oferecem respostas razoáveis às demandas do mercado. Nesta banda, a Law and Economics analisa o impacto jurídico na economia em sua perspectiva interna, não se preocupando com campos distintos (MORAIS DA ROSA, 2009), procedendo um diagnóstico das consequências do Direito na estrutura econômica, a partir de conceitos previamente dados sobre a conformação do Direito, de Justiça, de Teoria do Direito e de Moralidade, alterando aquilo que estiver em desconformidade com seu objetivo final, qual seja, o crescimento econômico.

Por essa razão, a AED é muito mais que um simples método de interpretação do direito, ela materializa uma ruptura com o modelo hermenêutico ocidental. É uma forma de interpretar que parte de escolhas ideológicas pré-estabelecidas, não discutidas e encantadoras. A justiça passa a significar, pura e simplesmente, eficiência (MORAIS DA ROSA, 2009). 
Nesta baila, o julgador também não restou imaculado. A figura do juiz é deslocada para um novo local, onde este é visto como mero instrumento, após passar por um processo de "coisificação". Portanto, não é possui mais um papel central, gozando de titularidade democrática como preceituado pela Constituição, seu compromisso para com a totalidade é aviltado quando o magistrado se torna um mero interlocutor daquelas ideias pré-estabelecidas por agentes difusores da doutrina econômica (KELLER DO VALLE, 2015, p. 166), passa, nesses termos, a ser um servo acrítico da doutrina mercadológica.

Claro exemplo da utilização da AED no sistema jurídico brasileiro é a instrumentalização da Reserva do Possível. Tribunais superiores têm assumido uma postura de consideração dos Direitos Fundamentais em relação aos seus respectivos custos para o Estado, no intuito de sonegar alguns direitos da sociedade, em especial, aqueles de cunho social. Em outras palavras, trata-se do "econômico" inviabilizando a garantia de tais direitos e, consequentemente, tornando inefetivas as normas constitucionais fundamentais.

Pode-se citar, de igual sorte, como fundamental para "legitimar" e positivar a reclassificação dos direitos fundamentais a partir do próprio texto constitucional a chamada Reforma Gerencial do Estado, concebida pela Emenda Constitucional n. 19/1998, também embasada pela teoria dos custos dos direitos (MORAIS DA ROSA; MARCELINO JÚNIOR, 2009, p. 13). Por meio da referida reforma foi instituído na Constituição o princípio da Eficiência Administrativa, o qual, por sua vez, não foi considerado como mais um princípio norteador da administração pública, assomado ao rol do artigo 37. O princípio, através do discurso de salvaguarda da probidade do erário nacional, leitura puramente economicista, passou a ser paradigma para os demais princípios constitucionais.

Diante de tudo aqui exposto, a racionalidade de "Justiça", diminuída a juízos de eficiência, desvincula uma ampla gama de direitos, inclusive alguns de cunho fundamental, do suporte valorativo e material preconizado pelo projeto do segundo pós-guerra, incluindo-se a própria Constituição brasileira. A AED se transmuta, nesses moldes, em um verdadeiro projeto de preponderância do econômico sobre o político usando como meio o Direito, tornando-se, sem sombra de dúvidas, um iminente risco de abalo para a democracia.

\section{A DISSEMINAÇÃO DAS POLÍTICAS DE AUSTERIDADE}


Desde a sedimentação do arcabouço teórico da Análise Econômica do Direito, esta tem sido aplicada, bem como fomentada através da influência dos novos atores do cenário global, pelos mais diversos sistemas jurídicos ao redor do planeta. Nesse capítulo, apresentar-se-á alguns exemplos da instrumentalização da referida teoria, tanto na esfera do Direito europeu, por meio da análise da atuação da Troika durante a crise financeira de Portugal, quanto no âmbito jurídico brasileiro, quando da realização da chamada Reforma Administrativa, levada a feito no ano de 1998 pela Emenda Constitucional n. 19.

Salienta-se que criação da Troika se deveu a um gap político e jurídico no Tratado de Maastricht. Este, por sua vez, era o responsável por impedir que paísesmembros da zona do euro com problemas de liquidez (SOARES, 2015, p. 109) recebessem ajuda de outras partes interessadas dentro da união monetária, a exemplo do Banco Central Europeu, outras instituições europeias e até mesmo de outros países-membros da União Europeia.

O movimento inicial para o estabelecimento do que hoje concebemos como a Troika teve origem com a decisão dos líderes da zona em conceder empréstimos bilaterais para a Grécia, em meados de 2010, com a implementação de um pacote de auxílio que continha uma participação considerável de fundos do FMI (SOARES, 2015, p. 109). Em consonância com o discurso dos líderes dos países europeus à época, a ajuda remetida para a Grécia estaria sujeita ao cumprimento de algumas condições, bem como a fiscalização por parte da Comissão Europeia, com ligação ao Banco Central Europeu, juntamente do Fundo Monetário Internacional.

Por conseguinte, a Troika representa um grupo de trabalho composto pela Comissão Europeia, Banco Central Europeu e pelo Fundo Monetário Internacional, e é responsável pela negociação de possíveis programas de assistência financeira para os países da União Europeia que ultrapassam crises econômicas. Como igualmente demonstrado, a Troika é incumbida de realizar fiscalizações periódicas naquilo que diz respeito às medidas para efetivação dos pacotes de ajuda construídas pelos países auxiliados (SOARES, 2015, p. 109).

Portugal, por sua vez, solicitou suporte financeiro um ano após a Grécia, em abril de 2011. A partir disso, o principal desafio enfrentado pelas autoridades portuguesas foi o de ter suas medidas contra a crise econômica aprovadas pelo controle técnico do Banco Central Europeu, da Comissão Europeia e do FMI. Por outro 
lado, no intuito de ser contemplado com os polpudos empréstimos das supramencionadas agências (SOARES, 2015, p. 117), Portugal comprometeu-se a estabilizar seu orçamento interno, através do aumento de impostos e de cortes de custos, e de realizar reformas estruturais na sua administração estatal.

Sob a forte pressão oriunda da supervisão da Troika, o governo português iniciou um movimento frenético para aprovar medidas, no que concerne aos custos do governo, que reduziram substancialmente o salário de funcionários públicos, cortaram o pagamento de aposentadorias, representaram a redução do financiamento para o sistema nacional de saúde português, fecharam hospitais, escolas públicas, tribunais e outros edifícios de prestação de serviço público por todo o país (SOARES, 2015, p. 118). Não obstante, houve uma diminuição considerável nos gastos despendidos pelo ente governamental para a assistência social, finalizando uma série de benefícios para desempregados e pessoas hipossuficientes.

Tais cortes de custos foram realizados ao mesmo tempo em que o parlamento nacional aprovou todas as propostas do governo acerca do aumento de impostos. Além disso, os impostos tiverem como complementação o aumento de taxas em prol dos mecanismos de segurança social e do serviço público de saúde, onerando, demasiadamente, a população mais vulnerável.

Após, os representantes da Troika fomentaram, de maneira contundente, uma campanha de privatizações que resultou na venda de aeroportos, empresas de produção e distribuição de eletricidade, o serviço de correios, transportes públicos e muitos outros ativos do Estado. Houve, do mesmo modo, uma vigorosa agenda para uma reforma estrutural do Estado português, acarretando severas modificações na legislação trabalhista, concorrencial e comercial, com escopo de diminuir os custos de produção e fomentar a flexibilidade das relações de trabalho (SOARES, 2015, p. 118). A burocracia interna do governo, tal qual o Poder Judiciário, passaram por reformulações de base, as quais alteraram profundamente as noções acerca do direito administrativo local.

Outrossim, os desdobramentos da aplicação da Análise Econômica do Direito não se restringiram ao velho continente. O Brasil, em igual modo, encontrou-se impelido a levar a efeito significantes alterações no âmbito do direito público, especialmente naquilo que diz respeito ao gerenciamento da máquina estatal sob a égide do princípio da eficiência, como depreende-se da reflexão acerca da intitulada Reforma Administrativa de 1998. 
A inserção do princípio da eficiência, através da Emenda Constitucional n. 19, surgiu acompanhada de uma ampla reformulação estatal, destinada a dar diferentes moldes às possibilidades de intervenção do Estado, guinando a administração pública para a direção de um modelo de matiz gerencial (STRINGARI, 2010, p. 51). Ademais, é fundamental notar que o principal motivo para a construção da referida Emenda foi consenso de que se necessitava atender, em caráter emergencial, as atualizações do modelo de Estado Social que, lento e burocrático, não mais atendia às demandas sociais, políticas e, principalmente, econômicas daquele momento.

Não se pode olvidar, portanto, que em função do desenvolvimento da economia, encabeçado pelo espraiamento do neoliberalismo a partir do século $\mathrm{XX}$, a Emenda Constitucional 19, de 1998, inseriu o princípio da eficiência no bojo da Constituição, ao adicionar a referida previsão no caput do artigo 37 da Carga Maior como o norteador de toda a administração do Estado (MABTUM, 2015, p. 267).

Tal constatação é cristalina quando extraídos os objetivos perseguidos pela reforma da Mensagem presidencial 886/95, a qual, posteriormente, daria origem a Proposta de Emenda Constitucional 173/95, convertida, ainda mais tarde, na EC 19. Pode-se elencar como as razões determinantes para a Reforma Administrativa: a) Crise do Estado e consequente má intervenção daquele na economia, ocasionando um desmonte no aparelho estatal e estagnação econômica; b) a reforma se fazia indissociável a reestruturação do Estado e de sua atuação, no intuito de instrumentalizar o equacionamento consistente em momentos de crise; c) quando da transição para a democracia, o Brasil já se encontrava em meio a uma profunda crise econômica, em razão disso, a manutenção de uma administração pública verticalizada, rígida e hierárquica é sem razão, fazendo-se imperioso o apontamento do Estado em direção da eficiência (MENSAGEM n. 886/95, p. 24-25).

Estes seriam alguns dos argumentos que, segundo os proponentes da EC em tela, justificariam a necessidade de se modificar a concepção de Estado, superando um vazio burocrático que vinha transformando a Administração Pública em obstáculo ao crescimento nacional. Em linhas gerais, a mudança formal da Constituição de 1988 interferiu nas mais diversas esferas do setor público, desde as políticas de admissão de pessoal e remuneratória, bem como na descentralização de funções das entidades administrativas (BULOS, 1998, p. 70). Dentre alguns outros aspectos, diferentes técnicas de gestão foram adicionadas às alterações constitucionais, sob o principal 
argumento de que tais medidas impulsionariam a eficiência e o crescimento econômico do Brasil.

\section{CONSIDERAÇÕES FINAIS}

Por fim, conclui-se que os intensos movimentos globalizatórios, intensificados após o fim da Segunda Guerra Mundial, abriram caminho para a formação de instituições de cunho transnacional, as quais passaram a pairar os horizontes das esferas pública e privada. Nessa toada, com escopo de viabilizar cada vez mais a liberalização dos mercados, tais instituições fomentaram o espraiamento da chamada Análise Econômica do Direito, a qual elaborou uma releitura do estudo do Direito, por meio do uso dos critérios da ciência econômica, como observado nos casos da Reforma Administrativa, em 1998, no Brasil e a atuação da Troika em meio a crise financeira portuguesa, ambas tendo a austeridade como suas bases para levar a feito as alterações propostas.

Com o desenvolvimento da globalização, espaços de debilidade foram preenchidos, como resultado direto da fragilização dos tradicionais atores nacionais, por uma agenda de interesses transnacionais constituída através de instituições novas, de difícil caracterização à luz do glossário político-jurídico da modernidade. A tradicional homogeneidade historicamente encontrada tanto no pensamento político, como na dogmática jurídica, dissipou-se. Instalou-se, a partir de então, um cenário de imensa inquietude institucional, onde a antiga organização estatal e os indivíduos depararam-se com uma sensação de profunda hesitação. Por assim dizer, a força motriz do Direito já não mais são anseios de limitação jurídica dos poderes estatais absolutos, mas a regulação de dinâmicas policêntricas atreladas diretamente com a circulação de modelos, capitais, pessoas e instituições distribuídos em espaços físicos e virtuais.

Diante do inegável empoderamento de tais Instituições Transnacionais, ferramentas capazes de facilitar a atuação e a livre circulação do mercado financeiro global foram desenvolvidas em um ritmo frenético desde meados do século $X X$. Ressalta-se, nesse quadro, a figura da Análise Econômica do Direito como um subproduto da proliferação do ideário neoliberal no campo da ciência jurídica. A corrente de pensamento em questão procurou transformar o Direito, o qual estaria ainda em um estado pré-científico, incapaz de se amoldar a nova realidade mundial, 
pautada pela profunda crise do Estado de Bem-Estar Social, em uma ciência na verdadeira acepção do termo, racional e positiva, e, no intuito de adimplir com seu objetivo, realizaria uma análise do fenômeno do Direito como um todo em consonância com os princípios, categorias e métodos empregados pela Economia.

Não sem razão, a Análise Econômica do Direito passou a permear e pautar o processo de criação legislativa nas mais diversas regiões do planeta. A atuação da Troika em Portugal, durante a crise financeira daquele país a partir do ano de 2010, é um claro exemplo dessa situação, na medida que, como contrapartida a concessão de diversos empréstimos, exigiu do governo português inúmeras reformulações de sua legislação, direcionando o país para a ideia de austeridade. De igual forma, observa-se a mesma situação, em território brasileiro, quando da realização da Reforma Administrativa, com a promulgação da Emenda Constitucional n. 19, que elevou o princípio da eficiência como corolário da Constituição Federal, o qual, desde então, passou a ditar as políticas públicas e até mesmo o próprio judiciário nacional, por meio de uma ampla reforma do Estado no sentido de uma espécie de austeridade institucional.

\section{REFERÊNCIAS BIBLIOGRÁFICAS}

BULOS, Uadi Lammêgo. Reforma Administrativa: Primeiras impressões. Revista Direito Administrativo, Rio de Janeiro, v. 214, p.69-98, dez. 98.

BRASIL, Deilton Ribeiro. Empresas Transnacionais sob o Império da Nova Ordem Mundial e Sua Integração no Direito Internacional. Revista dos Tribunais, Belo Horizonte, v. 792, p.35-62, out. 2001. Disponível em: <http://revistadostribunais.com.br/maf/app/resultList/document?\&src=rl\&srguid=i0ad6 007900000157475f9c8cfdd396a0\&docguid=le3702fd0f25011 dfab6f010000000000\& hitguid=le3702fd0f $25011 \mathrm{dfab6f0} 10000000000 \&$ spos $=4 \&$ epos $=4 \& \mathrm{td}=908 \&$ context $=18$ \&crumb-action=append\&crumb-

label=Documento\&isDocFG=false\&isFromMultiSumm;=\&startChunk=1\&endChunk=1 >. Acesso em: 01 set. 2017.

CHIARELLA, Luigi. Human Rights and Transnational Companies: Responsability Without Accountability. Bocconi Legal Papers, Genoa, v. 185, p.185-196, abr. 2014.

COTTEREL, Roger. What is Transnational Law? Law \& Social Inquiri, London, v. 37, p.500-524, 2012. 
CRUZ, Paulo Márcio; OLIVIERO, Maurizio. Fundamentos de Direito Transnacional. In: ROSA, Alexandre Morais da; STAFFEN, Márcio Ricardo. Direito Global: Transnacionalidade e Globalização Jurídica. Itajaí: Univali, 2013. p. 33-49.

GLENN, H. Patrick. Transnational Common Laws. Fordham International Law Journal p. 457-471. 2006.

HELD, David. Democracy and the Global Order: From the Modern State to Cosmopolitan Governance. Stanford: Stanford University Press, 1995. p. 11.

HEINEN, Luana Renostro. A Análise Econômica do Dirieto de Richard Posner e os Pressupostos Irrealistas da Economia Neoclássica. In: POMPEU, Gina Vidau Marcílio; GONÇALVES, Everton das Neves. Direito e Economia I. Florianópolis: Conpedi, 2014. p. 314-333. Disponível em: <http://www.publicadireito.com.br/artigos/?cod=991c0955da231335>. Acesso em: 03 set. 2017.

JESSUP, Philip C.. Transnational Law. New Haven: Yale University Press, 1956. p. $12-40$.

KHANNA, Parag. Como Governar o Mundo: Os caminhos para o renascimento. Rio de Janeiro: Editoria Intrínseca, 2011. Tradução de: Berilo Vargas.

LAW, Stephanie. From Multiple Legal Cultures to One Legal Culture: Thinking about Culture, Tradition and Identity in European Private Law Development. Utrecht Journal of International and European Law, p. 68-89, 2015.

MABTUM, Matheus Massaro. O Princípio da Eficiência Administrativa Pós Emenda Constitucional 19/98. Revista Direitos Sociais e Políticas Públicas (unifafibe), São Paulo, v. 3, n. 2, p.265-280, maio 2015.

MARCELLINO JÚNIOR, Júlio César. Princípio Constitucional da Eficiência Administrativa: (des)encontros entre economia e direito. 2. ed. Florianópolis: Habitus, 2009. p. 111-157 (Coleção Jacinto Nelson de Miranda Coutinho).

MARCELLINO JÚNIOR, Júlio César. Neoliberalismo, Liberdade e Mal-Estar: (Des)Escontros Entre Hayek e Freud. Uma Releitura em Tempos de Crise. In: VALLE, Juliano Keller do; MARCELLINO JÚNIOR, Júlio César; AQUINO, Sérgio Ricardo Fernandes de (Org.). Direitos Fundamentais, Economia e Estado: Reflexões em Tempos de Crise. Florianópolis: Empório do Direito, 2015. p. 179-191.

OLIVIERO, Maurizio; STAFFEN, Márcio Ricardo. II Diritto Globale: giustizia e democrazia oltre lo stato (Sabino Cassese). Seqüência: Estudos Jurídicos e Políticos, Florianópolis, p. 357-360, jul. 2013. ISSN 2177-7055. Disponível em: $<$ https://periodicos.ufsc.br/index.php/sequencia/article/view/21777055.2013v34n66p3 57/25226>. Acesso em: 30 ago. 2016. doi: http://dx.doi.org/10.5007/21777055.2013v34n66p357.

Radu, Liviu. Transnational Companies and Their Role in Globalization. Lex ET Scientia International Journal, p. 397-406, 2009. 
ROSA, Alexandre de Morais da; LINHARES, José Manuel Aroso. Diálogos com a

Law \& Economics. Rio de Janeiro: Editora Lumen Juris, 2009.

ROSA, Alexandre de Morais da. O Judiciário Entre a Garantia do Mercado ou dos Direitos Fundamentais: A "resposta correta", com Lênio Streck. Revistas de Estudos Constitucionais, Hermenêutica e Teoria do Direito, São Leopoldo, p.1-8, jun. 2009.

ROSA, Alexandre de Morais da; MARCELLINO JÚNIOR, Júlio César. Os Direitos Fundamentais na Perspectiva de Custos e o seu Rebaixamento à Categoria de Direitos Patrimoniais: Uma leitura crítica. Revista da Acadêmia Brasileira de Direitos Constitucional, Curitiba, n. 1, p.7-28, dez. 2009.

SOARES, Antonio Goucha. EU Commission participation in the Troika mission: is there a European Union price to pay?. Revista Brasileira de Política Internacional, [s.I.], v. 58, n. 1, p.108-126, jun. 2015. FapUNIFESP (SciELO). http://dx.doi.org/10.1590/0034-7329201500106.

STAFFEN, Márcio Ricardo. Hegemonia e Direito Transnacional?. Novos Estudos Jurídicos (Online), v. 20, p. 1166, 2015

STAFFEN, Márcio Ricardo. Interfaces do Direito Global. Rio de Janeiro: Lumen Juris, 2015.

STRINGARI, Amana Kauling. A Eficiência como Princípio Orientador da Atividade Admistrativa. Revista Bonijuris, Curitiba, v. 562, p.51-57, set. 2010. Disponível em: <https://app.vlex.com/\#WW/vid/235458761>. Acesso em: 04 set. 2018. 